\title{
دراسة تجريبية لبعض غرز التطريز اليدوية في تنفيذ الجونلات الجلدية للاستفادة هنها في المشروعات الصغيرة
}

\author{
إعلاد \\ د/ رباب طاهر عبد اللطيف \\ أ.م.ده/ أملـــمحد الفيومحسـ \\ مدرس الملابس والنسيج

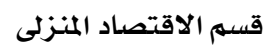 \\ أستاذ مساعد الملابس والنسيج

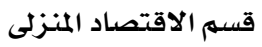 \\ كلية التربية النوعية - جامعة دمياط الاقئل المزئ \\ كلية التربية النوعية - جامعة دمياط الافتئد المنزل
}

مجلة بحوث التربية النوعية ـ جامعة المنصورة

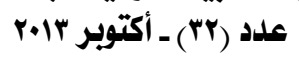




\title{
دراسة تجريبية لبعض فرز التطريز اليدوية فى تنفيذ الجونلات البلدية للإستفادة هنها فى المشروعات الصغيرة
}

\author{
إعداد \\ د/رباب طاهر عبد اللطيف**

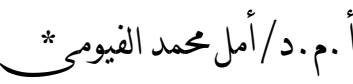

\section{همدص الدراسة:}

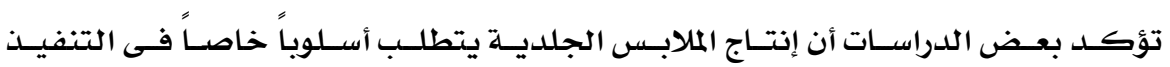

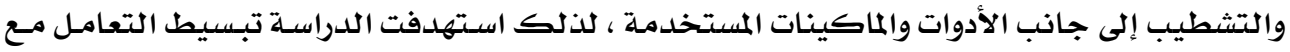

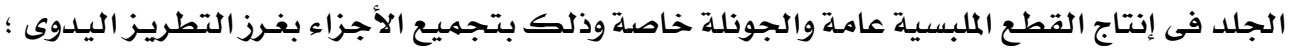

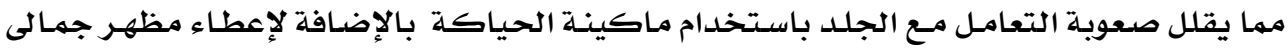

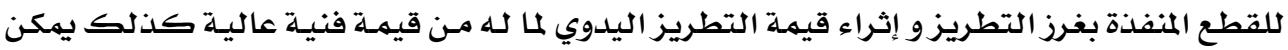
عمل مشاريع صغيرة تساعد الأفراد على حياة أفضل.

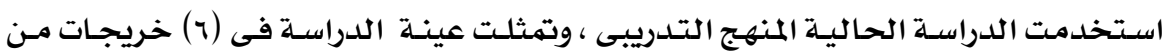

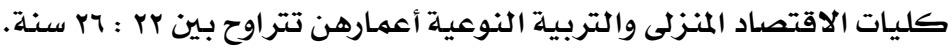
وكانت أهم نتائج الدراسة :

ملائمـة غرزة الفرع لتجمبـع أجزاء الجـونلات الجلديـة المنفـذة مـن ناحيـة كل مـن الأداء الوظيفى الجـي

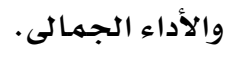

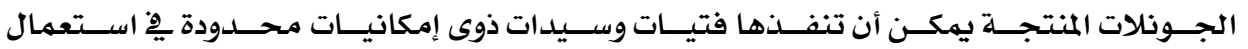

ماكينات الحياكة.

• يمكن إقامـة مشروع صغير قائم على قطع ملبسية من الجلد الصناعى مجمعة بغرزة الفرع.

همدهة:

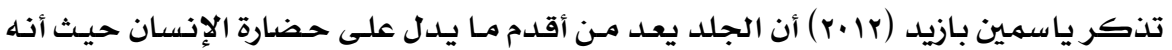

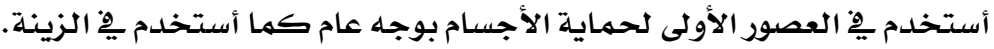

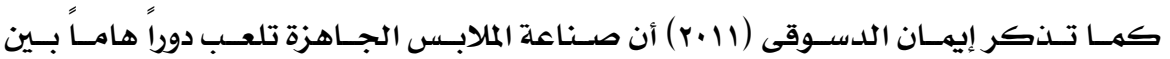

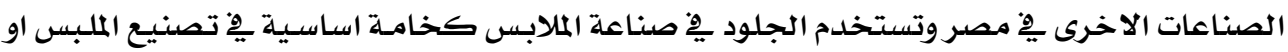

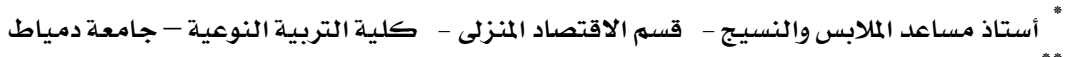

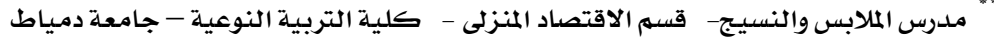


كخامـة مكملـة وتزينيـة وتنقسم الجلود الى جلـود طبعيـة وجلود صـناعية وقد ظهر الجلـد الصناعي كهماكاه للجلد الطبيعي.

وتعـد الصناعات الجلديـة أحسد القطاعـات الواعدة في الاقتصـاد القـومى حيـث يمثل نسبـة

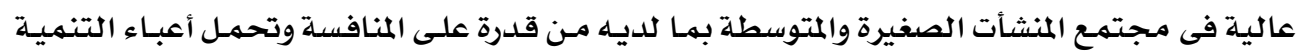
فى البـلاد.

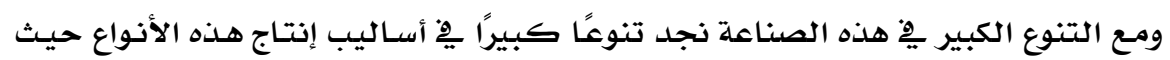

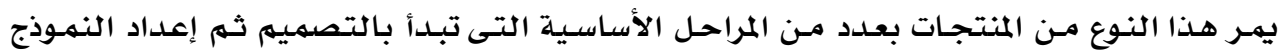

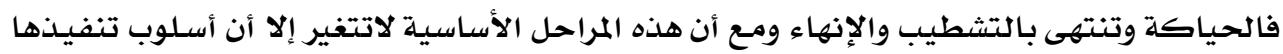

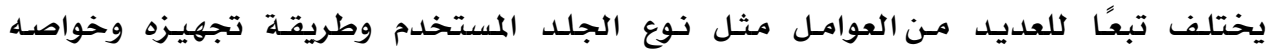
الطبيعية والكيميائية.

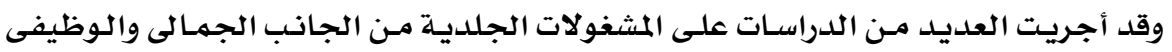

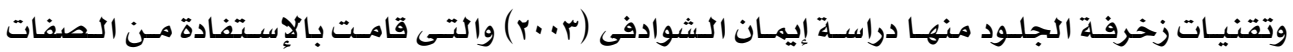

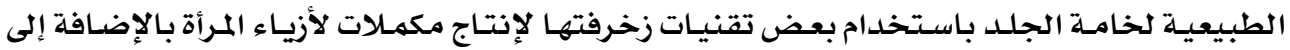

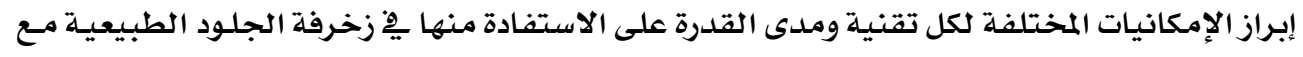

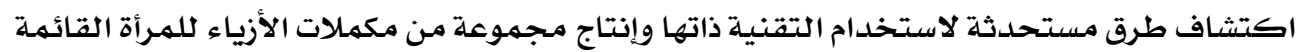

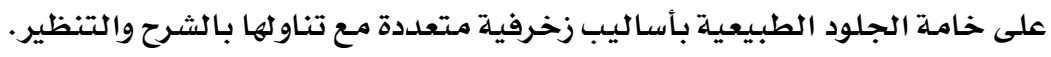

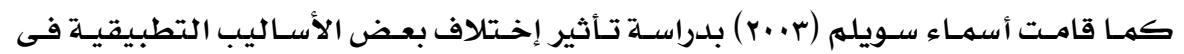

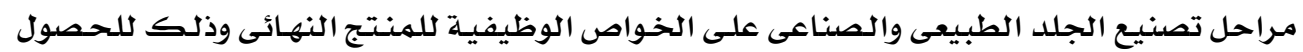

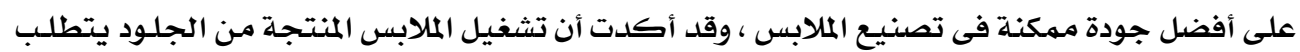

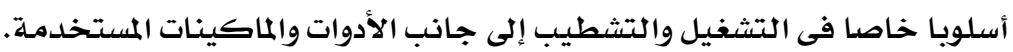

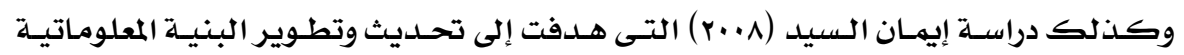

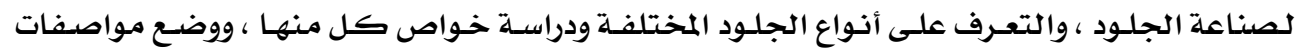

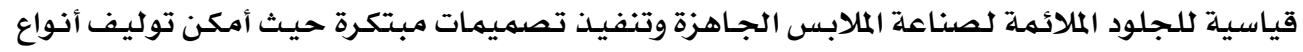

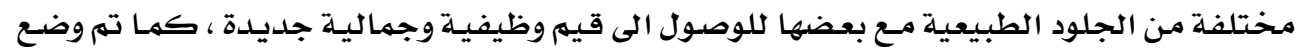
أسس وتقنيات حياكة الخامات الجلدية وتشطيبها والعناية بها.

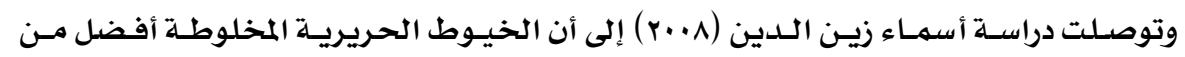

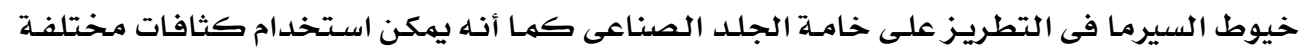

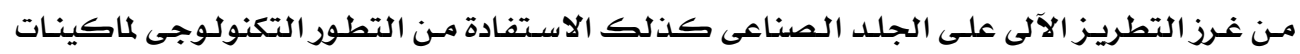

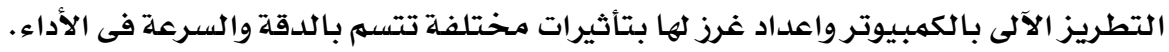

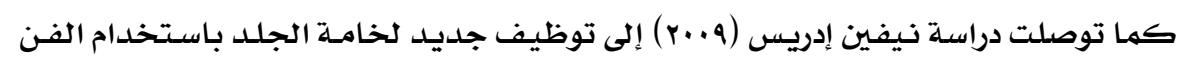

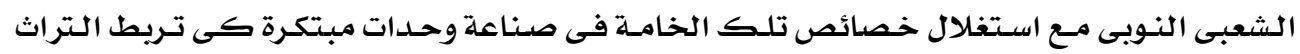

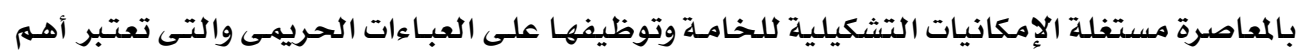


$+2$

قطعـة مـن ملابس المـرأة حيـث قـدمت العبـاءة الحريهـى بــكل يحـافظ على مفهومهـا مـن الناحيـة التقليدية والدينية.

كذلك دراسة أمانى بشرى ( • +r) والتى قامت بإجراء تطبيقات تجريبية علي بعض عينات

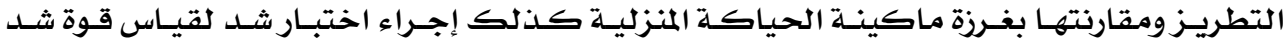

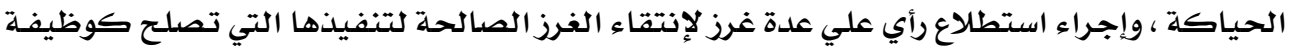
نفعية وجمالية.

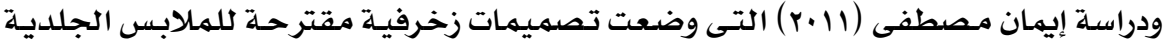

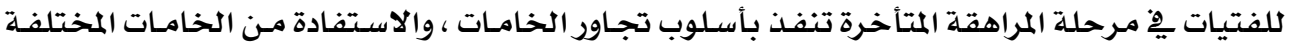

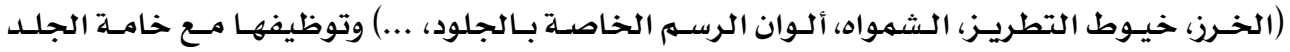

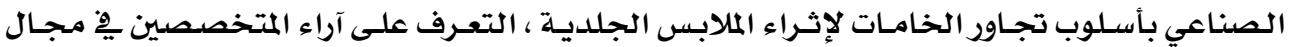

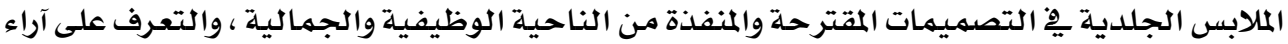

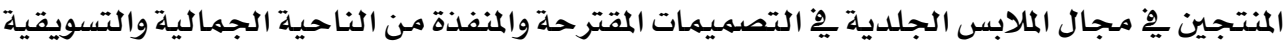
، زيادة تسويق الملابس الجلدية للفتيات يِّن مرحلة المراهقة المتأخرة.

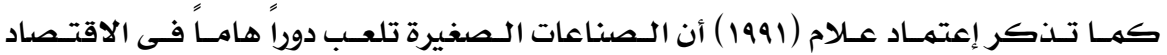

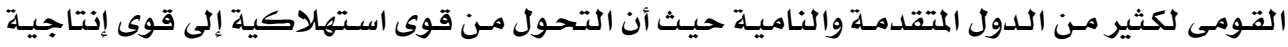

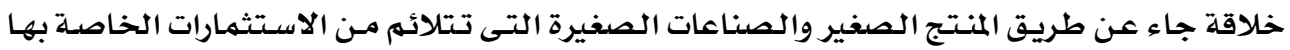

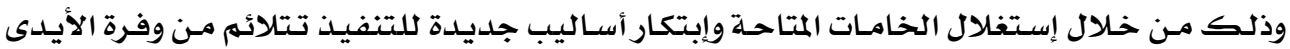

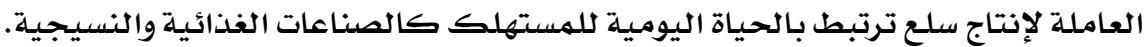

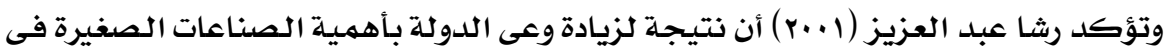

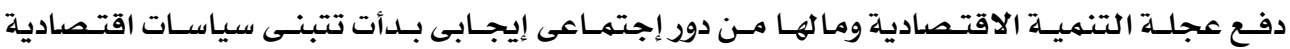

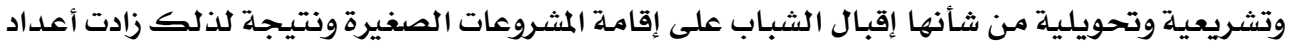

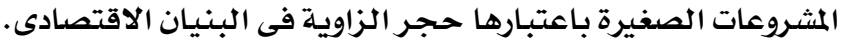

\section{وقد استفادت الباحثتان من الدراسات السابقة فى النقاط التالية:}

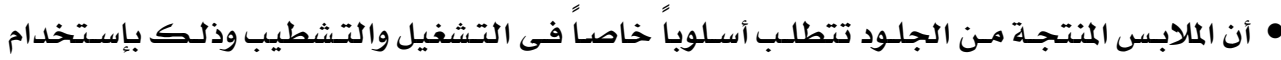
ماكينات خاصة للجلود. • أفضل أنواع الخيوط للتطريز على الجلد الصناعى هى الخيوط المخلوطة.

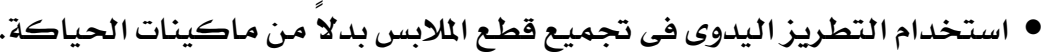
• استخدام التطريز بالخيط والخرز فى ملابس الفتيات المصنعة من الجلد.

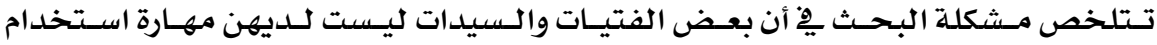
ماكينة الحياكة أو لا تفضلن استخدامها ولديها مهارة التطريز اليدوي ، ونظرا لغلاء الأسعار فهـن 


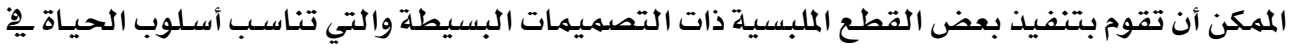

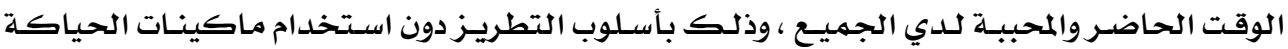

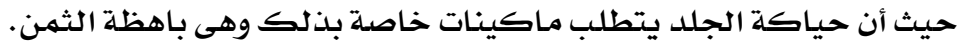

\section{التساؤلات البمثينة:}

\section{يمكن صياغة مشكلة البحث فى التساؤلات التالية:}

ا ـ ماهى إمكانية تنفيذ الجونلة الجلدية بإستخدام بعض غرز التطريز اليدوى.

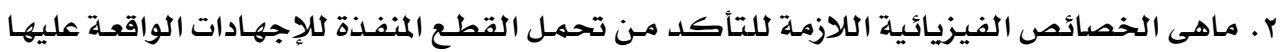
أثناء الإستهلاك.

r. مامدى تحقيق غرز التطريز اليدوى على الجلد للجانب الوظيفى للقطع المنفذة. ع. مامدى تحقيق غرز التطريز اليدوى على الجلد للجانب الجمالى للقطع المنفذة. ه. مامدى إمكانية إقامـة مشروع صغير قائم على تنفيذ قطع ملبسسية مـن الجلـد الصناعى بإسـتخدام غرز التطريز اليدوية.

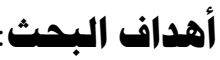

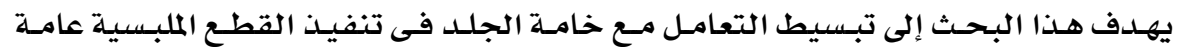

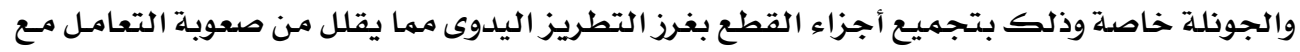

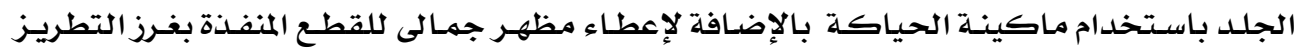

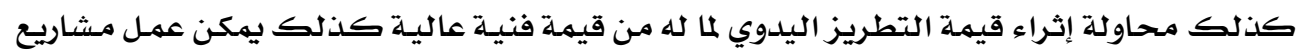

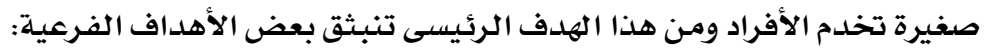
ا. ـ دراسـة الخصائص الفيزيائية للقطع المنفذة والتى تؤثر على عمرها الإستهلاكى. r. تحقيق غرز التطريز اليدوى المستخدمـة للجانب الوظيفى. r. تحقيق غرز التطريز اليدوى المستخلدمة للجانب الجمالى.

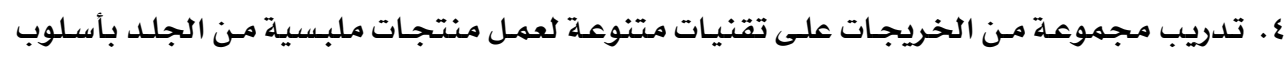

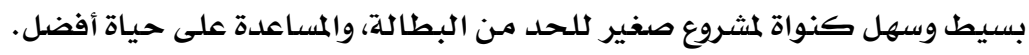

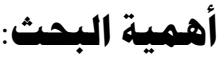

\section{ترجـع أهمية البحث إلى:}

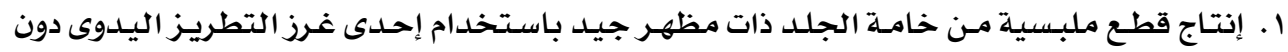
الحاجة الى ماكينة الحياكة. r. المشاركة فى حل مشكلة البطالة ، والحاجة لزيادة الدخل من خلال عمل مشروع صغير لا يتطلب مالب رأس مال كبير 


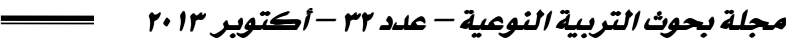

r. الإستفادة من تدريب الخريجات لعمل مشروع صغير لخلق فرص عمل متزايـدة لطالب العمل مـن

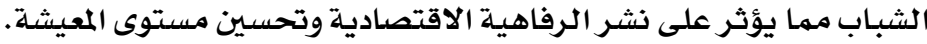

ع. قد يفتح هذا البحث الباب أمام بحوث مماثلة على قطع ملبسيه أخرى وكيفيـة الإسـتفادة منهـا و عمل مشروعات صغيرة تناسب فئات مختلفة.

هنهمج البمث:

يستخدم البحث المنهج التجريبى نظراً لمناسبته لطبيعة البحث وأهدافه.

هصطال

الجلود: Leather

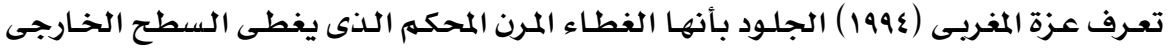

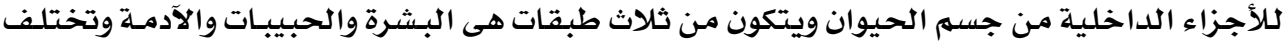

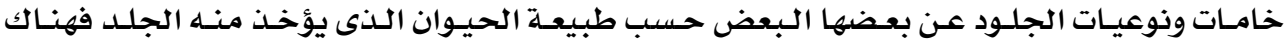

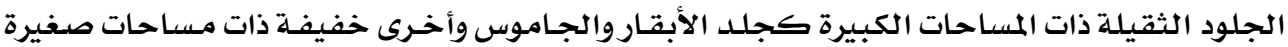
كجلد الغنهم والماعز.

Synthetic Leather : الجلود الصناعية

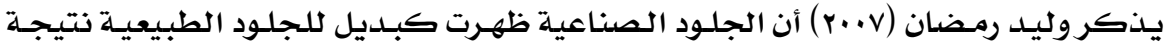

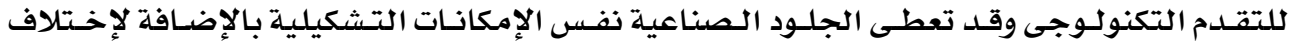

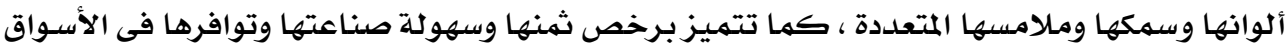

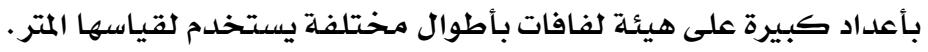
تذكر منى السويفى (1999) أن الجلود الصناعية تصنع مـن مـواد شمعيـة وراتنجيـة ولدائن ومواد عضوية مختلفة وهى تتكون من طبقتين هما : الطبقة العليا : وهى تمثل سطح الجلد وهى مصنعحة من مواد شمعية وراتنجية ولدائن ومواد عضوية. الطبقـة السفلى : وهى تكون فى صسورة نسيج شبكى بخيوط رقيقـة وضـيقة التكوين بامتـداد قطعـة

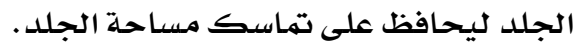

Embroidery : التطريز

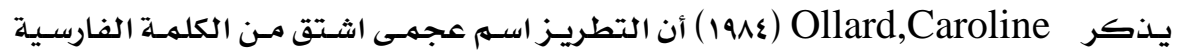

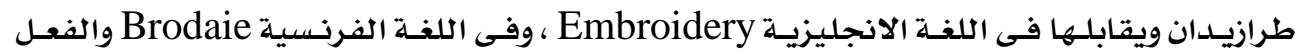
يطرز أى يحدث زخرفة أوحلية تطبق على هيئة مختارة من نسيج معين.

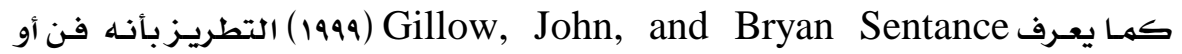
الحرفة اليدويـة لتزيـين النسيج أو غيرها مـن المواد باستخـدام إبـرة وخيط غزل ، التطريز يشمل أيضـا 


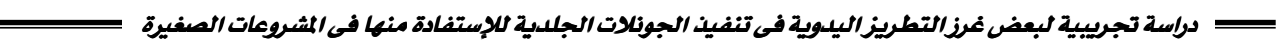
مــواد آخـرى مثـل المعـادن ، الـشرائط ، اللؤلـؤ ،الخـرز، الريـشات ، والترتـر .وغالبـاً مـا يكـون التطريـز للقبعات والمعاطف والبطانيات والقمصان والجوارب والجينز والجونلات.

Branch Stitch : غرزة الفرع

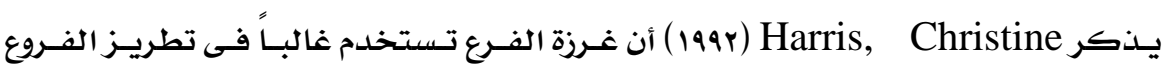

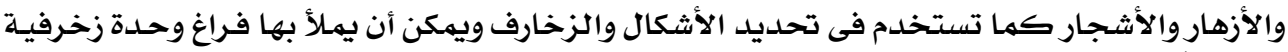

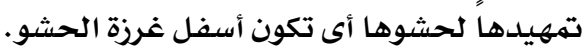

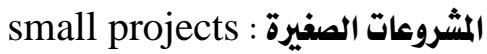

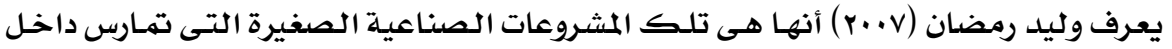

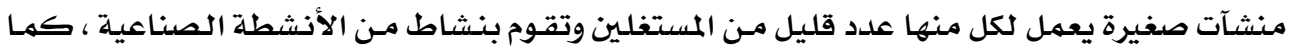

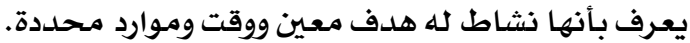

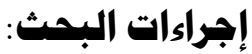

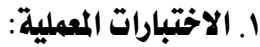

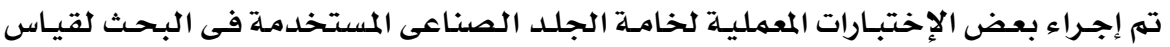

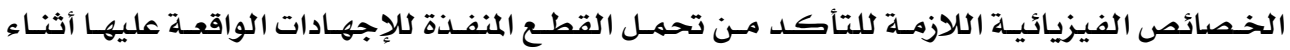
الإستهلاك ، وتتمثل فى الإختبارات التالية: أ) وزن المتر المريع ، وسمك الجلد الصناعى المستخدم. ب) قوة الشد ونسبة إستطالة قطع وصلة الخيط المستخدم. ج) قياس مستوى المظهرية بالتنظيف الجاف.

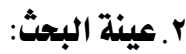

تم عرض البر نامج التدريبى على مجموعة خريجات مـن كليـات الاقتصـاد المـزلى والتربيـة

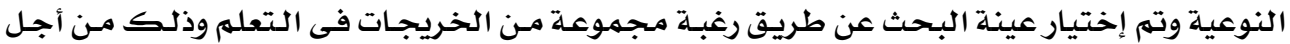

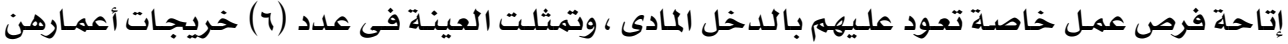

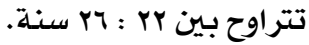

\section{r. تحديل محتوى البرنامج وتنظيمه:}

دراسـة مسحية للسوق المحلى وذلك للتعرف على أحلدث خطوط الموضسة فى الجـونلات عامـة والجلدية خاصدة وذلك لعرضها على المتدريات.

الإسـتعانة بالكتـب والموسـوعات العلميـة والأبحـاث والدراسـات السـابقة للإسـتفادة منهـا فى دي

كيفية تبسيط التعامل مـع الجلد الصناعى فى تنفيذ الجونلات دون إستخدام ماكينـة الحياكة. 


$$
\begin{aligned}
& \text { ع. أدوات البحث: } \\
& \text { • باترونات منفذة بالقياسات الأساسية. } \\
& \text { • التصميمات التى تم إختيارها للتنفيذ. } \\
& \text { • أقمشة من الجلد الصناعى متعددة الألوان. } \\
& \text { • خيوط تطريز من القطن المخلوط. } \\
& \text { • أدوات التفصيل والحياكة اللازمـة لإتمام العهل. }
\end{aligned}
$$

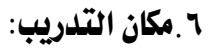

إحـدى معامـل الحياكـة بكليـة التربيـة النوعيـة جامعـة دميـاط حيـث روعى أن يكون المعهمل

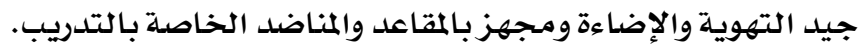

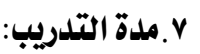

تم عمل (r) ورث عمل بواقع (ع) ساعات لكل ورثة وتم تقسيمها كالآتى :

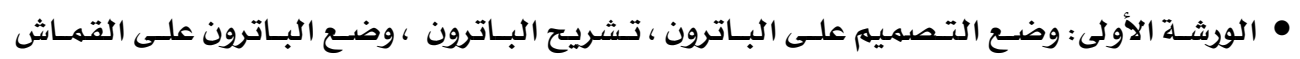

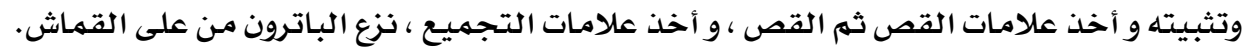

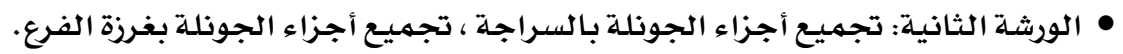

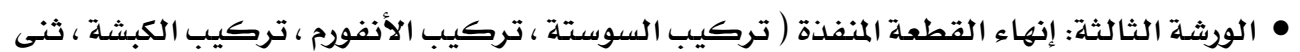

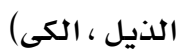

\section{وفيما يلى عرض للجونلات الجلدية المنفذة وتوصيفها:} القطعة الأولى المونى

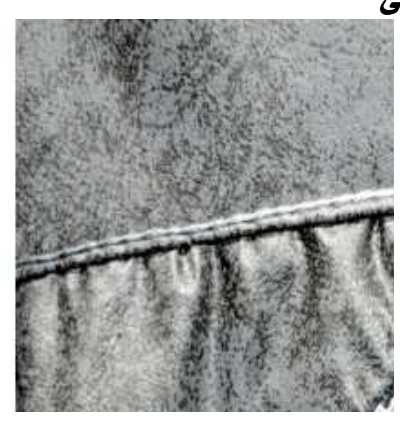

شكل الغرزة

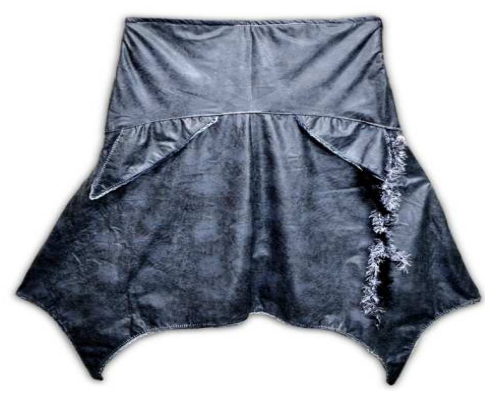

المنتج النهائى 


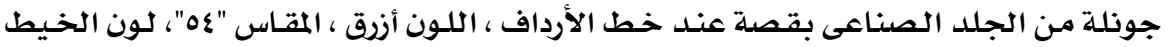

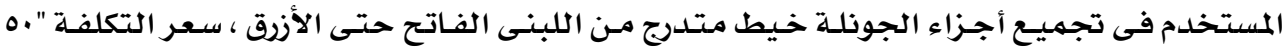

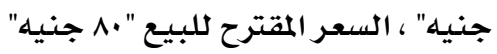

القطعة الثانية

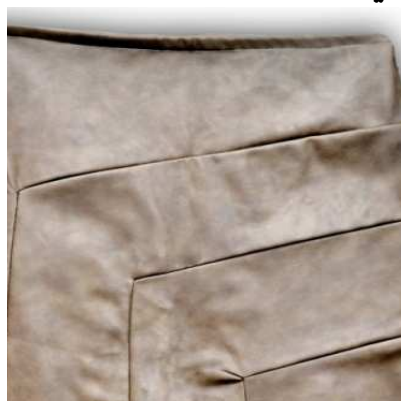

شكل الفرزة

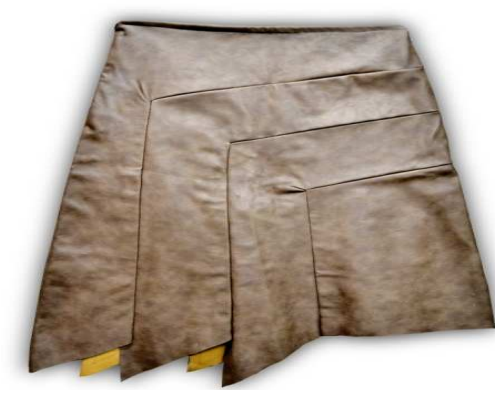

المنتج النهائى

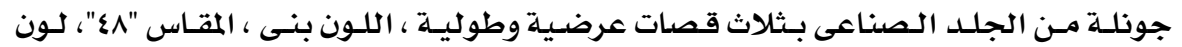

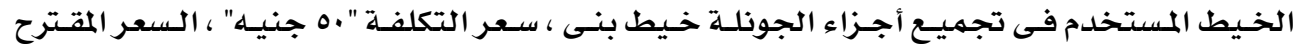
للبيع "•م جنيـه"

القطعة الثالثة
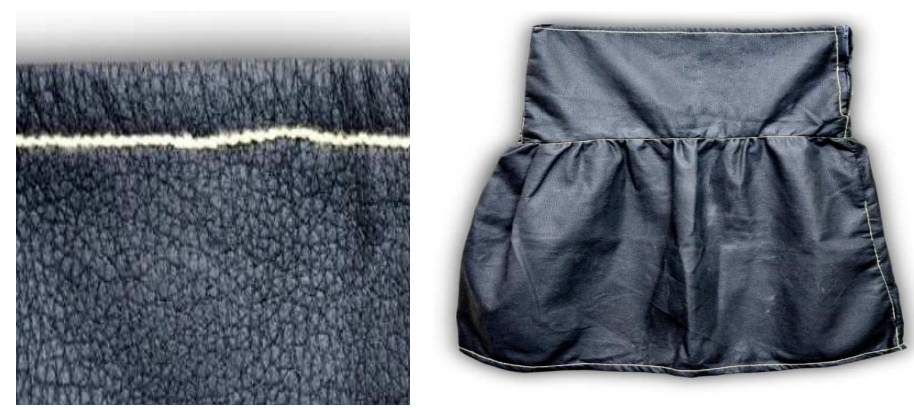

شكل الغرزة

$$
\text { المنتج النهائى }
$$

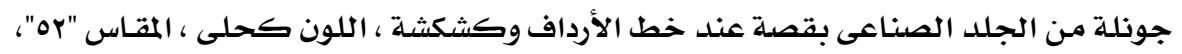

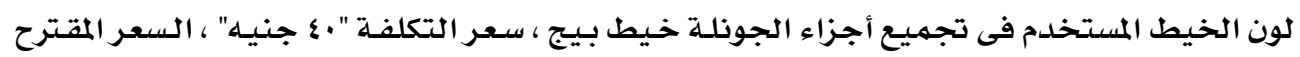
للبيع "ه7 جنيـه 


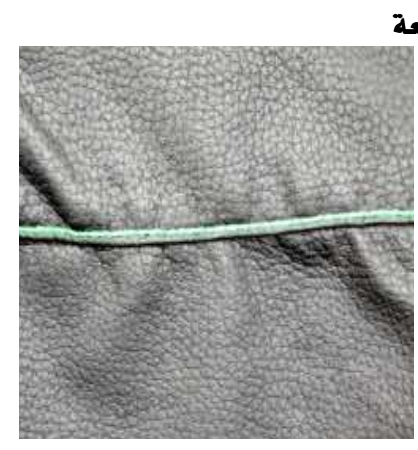

شكل الغرزة

القطعة الرابعة

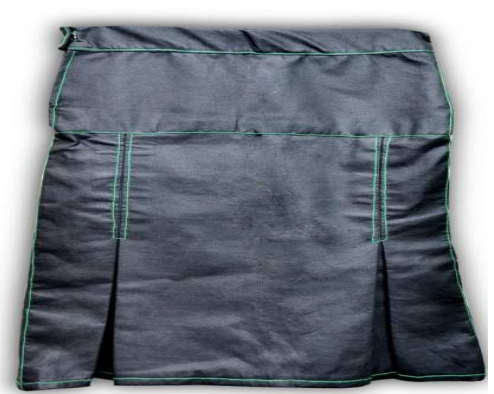

المنتج النهائى

جونلة من الجلد الصنـاعى بقصدة عند خط الأرداف وكـالونتين ، اللـون أسـود ، المقـاس " مه"،

لـون الخـيط المستخلـم فـى تجميـع أجـزاء الجـونلـة خـيط أخضـر ، ، سـعر التكلفـة ".0 جنيـه" ، السسعر

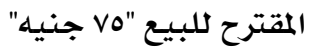

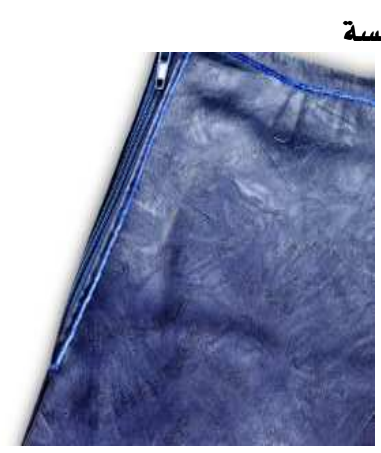

شكل الغرزة

القطعة الخامسة

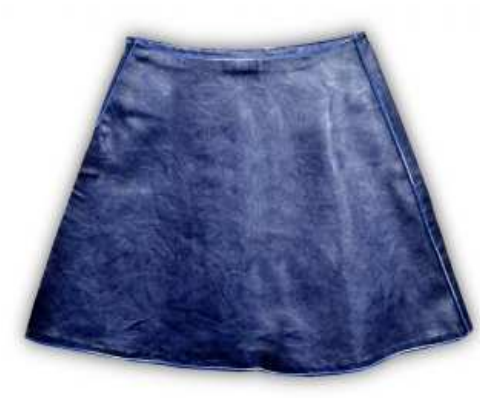

المنتج النهائى

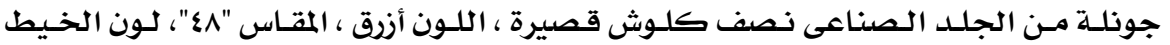

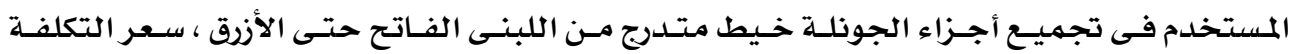

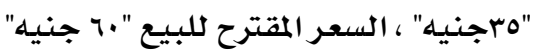




\section{القطعة السادسة}

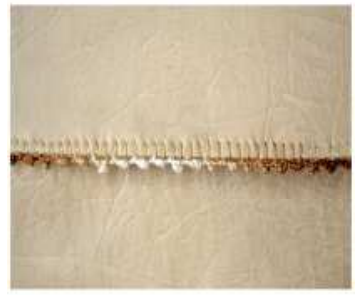

شكل الغرزة

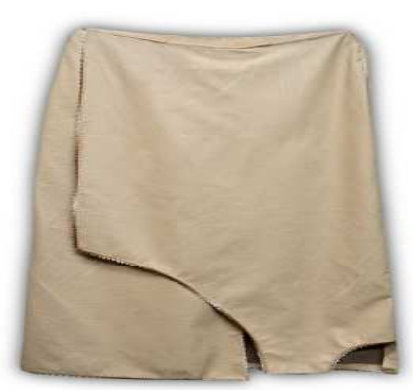

المنتج النهائى

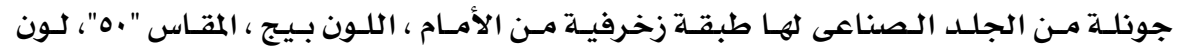

الخيط المستخدم فى تجميـع أجزاء الجونلة خيط متتدرج من البيج إلى البنى ، سعر التكلفة " .0 جنيه"

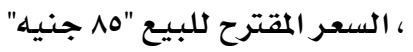

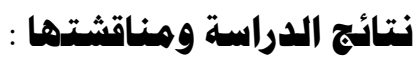
أولاً : النتائج المتعلة بالاختبارات المعلية: ا . وزن المتر المريع ، وسمك الجلد الصناعى المستخدم: . تم أخذ عينـة أبعادها · 1 × · ا وتم وزنها وقياس سهكها وفقـا للمواصفات القياسيـة والجـدول التالى يوضك ذلك

جلدول (1) وزن المتر المربع وسمك الخامة المستخدمة

\begin{tabular}{|c|c|c|}
\hline متوسط سمك القماش (م)) & متوسط وزن المتر المربع (جم) & الخامة \\
\hline $1, \cdot 9$ & $\sum 7 \wedge, 0$. & الجلد الصناعى \\
\hline
\end{tabular}

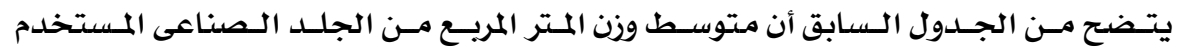
. r. قوة الشد ونسب إستطالة قطع وصلة الخيط المستخلم: تم تجهيز العينـة المحاكة بغرزة الفرع وثبتتها تماما فى المنتصف بـين فكى الجهاز وتعرضها لقوة الشد إلى أن تنقطع وتم تسسجيل أقصى حمل قاطع والجدول التالى يوضتح ذلك جدول (r) قوة الشد ونسبة الاستطالة

\begin{tabular}{|c|c|c|c|c|}
\hline \multicolumn{2}{|c|}{ نسبة الاستطالة (سه) } & \multicolumn{2}{|c|}{ قوة الشلد (كجم) } & \multirow{2}{*}{ نوع الخامة } \\
\hline فى اتجاه اللحمة & فى اتجاه السداء & فى اتجاه اللحمة & فى اتجاه السلداء & \\
\hline$\cdot, 01$ & $\cdot, Y r$ & 17 & $\$ 0$ & الجلد الصناعى \\
\hline
\end{tabular}




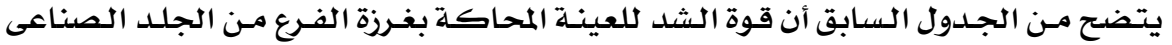

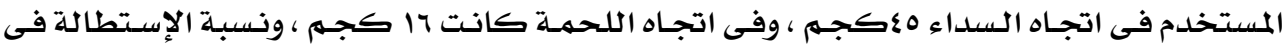

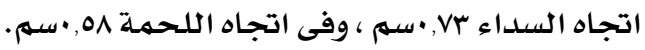
r. قياس مستوى المظهرية بالتنظيف الجاف:

تم قياس مستوى المظهرية للجلد الصناعى المستخدم بعد التنظيف الجـاف والجدول التالى ملى يوضتح ذلك

\begin{tabular}{|c|c|c|}
\hline الانحراف المعيارى & المتوسط & الاختبار \\
\hline •, VrI & $V, \Lambda T$ & مستوى المظهرية \\
\hline
\end{tabular}

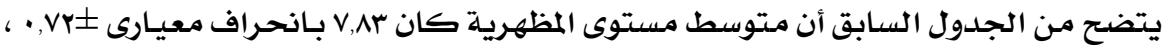

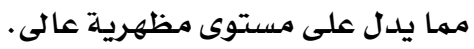
ثانياً : النتائج المتعلقة بالأداء المهارى الخاص بتنفيذ ماليذ الجونلات:

تم قياس الأداء المهارى الخاص بالمتدريات أثناء تنفيـذ الجـونلات عن طريق بطاقـة الملاحظة

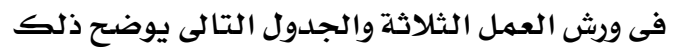

جدول (ع) نتائج بطاقة ملاحظة الأداء المهارى الخاص بتنفيذ الجونلات

\begin{tabular}{|c|c|c|c|c|c|}
\hline \multirow{2}{*}{ ע } & \multicolumn{3}{|c|}{ مستوى الأداء (نعم) } & \multirow[t]{2}{*}{ قائمة الأداك } & \multirow{2}{*}{ 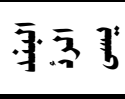 } \\
\hline & 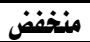 & متوسط & مرتفع مرت & & \\
\hline & & $\%$ & $\%$ & وضع التصميي على الباترون وتشريحه & \multirow{5}{*}{ 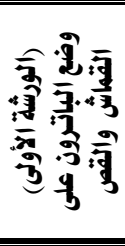 } \\
\hline & & $\%$ r. & $\%$. & |وضع الباترون على القماش بطريقة صحيحة & \\
\hline & & $\%$ & $\%$ & | أخذ علامات القص بطريقة صحيحة & \\
\hline & & $\% 10$ & $\%$ 10 & | القص بطريقة صحيحة & \\
\hline & & & $\% 1 \ldots$ & | أخذ علامات التجميع حول حدود الباتروز & \\
\hline & & $\%$ & $\%$ & |تجميع القصات بالسراجة & \multirow{4}{*}{ 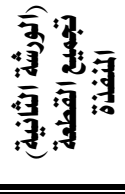 } \\
\hline & & $\%$ & $\%$ & |تجميع القصات بغرزة الفرع & \\
\hline & & & $\% 1$. & |تجميع خط الجنب بالسراجة & \\
\hline & & $\%$ & $\%$ & |تجيع خط الجنب بغرزة |الفرع & \\
\hline & & $\% 10$ & $\%$ ॥0 & |تركيب السوستة بالسراجة & \multirow{7}{*}{ 高 } \\
\hline & & $\% 10$ & $\%$. 0 & |تركيب السوستة بفرزة الفرع & \\
\hline & & $\%$ & $\%$ & |تركيب أنقورم الوسط بالسراجة & \\
\hline & & $\%$ & $\%$ & |تثبيت الأنفورم بغرزة الفرع & \\
\hline & & $\%$ & $\%$ & |تركيب الكبشة & \\
\hline & & $\% 10$ & $\%$ ^० & |ثنى الذيل & \\
\hline & & & $\%$ & |كى القطعة المنفذة من الظهر & \\
\hline
\end{tabular}


يتضح مـن الجـدول السـابق أن تقييم الأداء المهارى فى (الورشـة الأولى) كـان مستوى الأداء

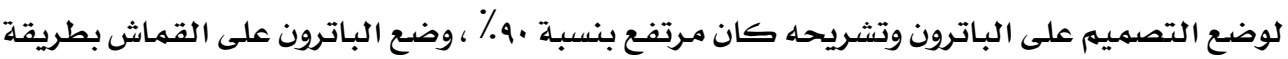

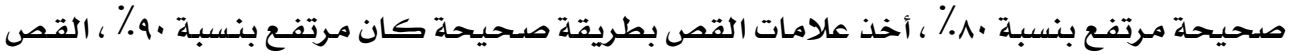

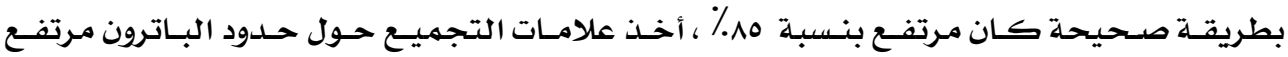

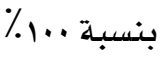

بالنسبـة لتقيـيم الأداء المهارى فى (الورثـة الثانيـة) كـان مستوى الأداء لتجميـع القـصـات

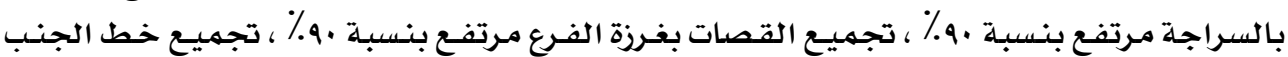

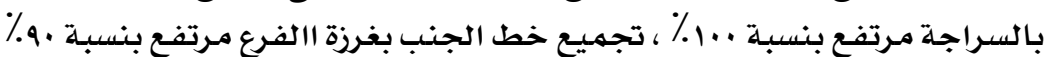

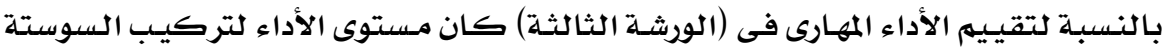

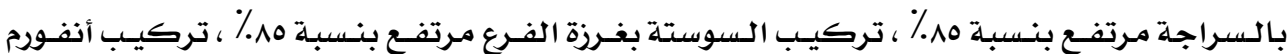

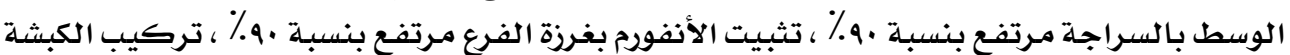

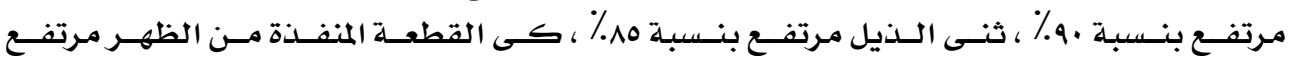

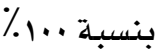

ثالثًا : النتائج المتعلقة بآراء المتخصصين تجاه الجوذلات المنفذة:

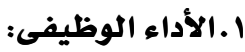

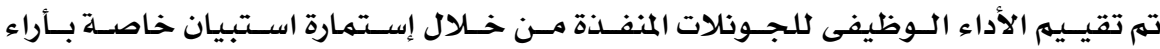

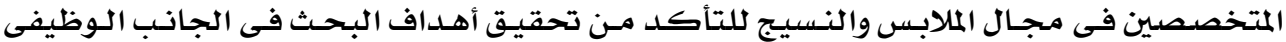
والجدول التالى يوضتح ذلك

جدول (ه) النسب المئوية لآراء المتخصصين نحو الأداء الوظيفى

\begin{tabular}{|c|c|c|c|}
\hline \multicolumn{3}{|c|}{ مستويات الأداs } & \multirow{2}{*}{ بنود التقويم } \\
\hline 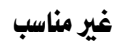 & مناسب إلى حلد ما & 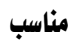 & \\
\hline & $\%$. & $\%$ & ملائمة التصميم مع خامة الجلا \\
\hline- & $\%$. & $\%$ & ملائمة الفرزة لتجميع القطعة المنفذة \\
\hline L & $\%$ & $\%$ & ملائمة الفرزة للتشطيب والإنهاء \\
\hline & $\%$ r. & $\%$ \%. & ملائمة سمك الخيط مع الجلد \\
\hline
\end{tabular}

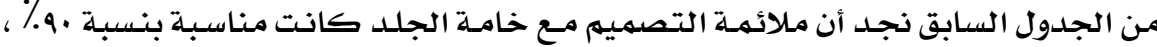

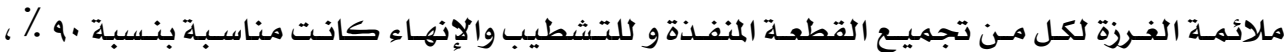

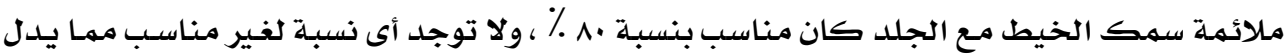

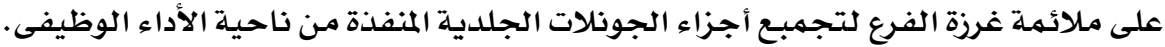




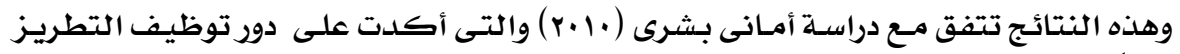

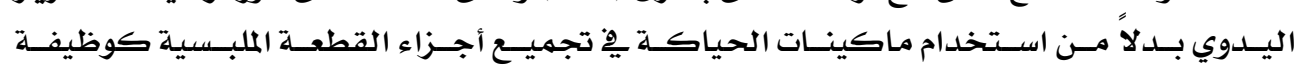
نفعية وجمالية.

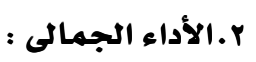

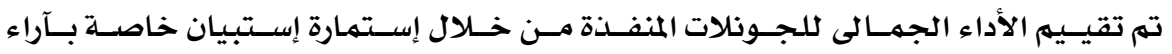

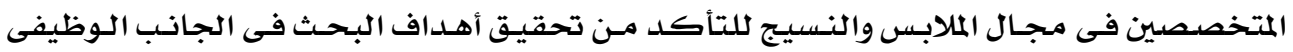
والجدول التالى يوضح ذلك مجين

جدول (7) النسب المئوية لآراء المتخصصين نحو الأداء الجمالى

\begin{tabular}{|c|c|c|c|}
\hline \multicolumn{3}{|c|}{ مستويات الأداء } & \multirow{2}{*}{ بنود التقويم } \\
\hline غير مناسب & إلى حلد ما & مناسب & \\
\hline & $\%$ r. & $\%$ \%. & ملائمة التصميم مع خامة الجلد \\
\hline - & $\%$. & $\%$ & ملائمة الفرزة مع الجلد \\
\hline 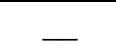 & $\%$ & $\%$ & ملائمة التشطيب النهائى \\
\hline$=$ & $\%$ r. & $\%$ \%. & ملائمة لون الخيط مع لون الجلد \\
\hline
\end{tabular}

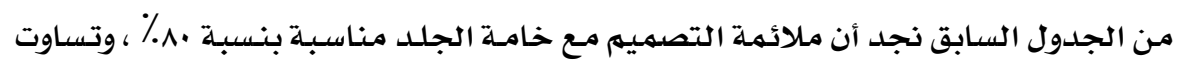

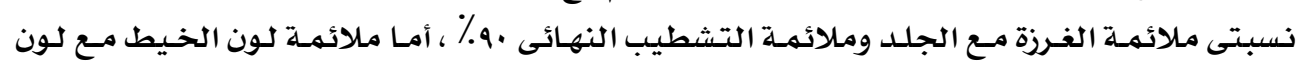

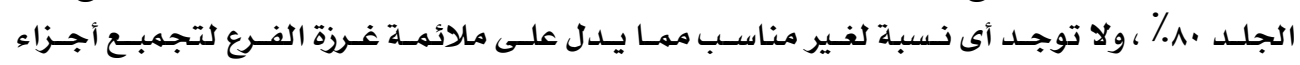

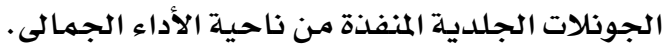

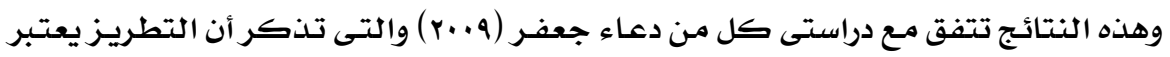

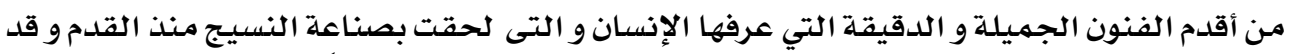

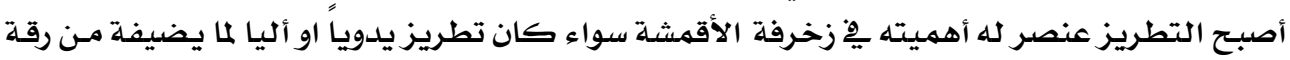

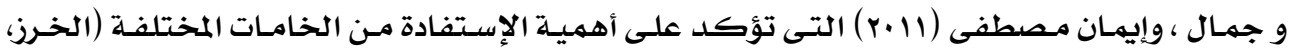

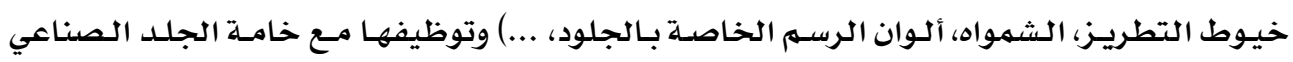

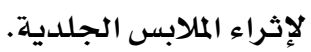
r. إمكانية إقامـة مشروع صغير قائم على القطعة المنفذة:

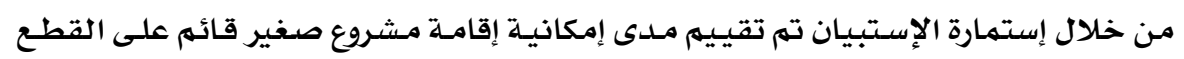
المنفذة ، والجدول التالى يوضح ذلك إستمارة الاستيّان 
لم= دراسة تجريبية لبعض غرز التطريز السيلوية فى تنفيذ الجونلات الجلسية لإستفادة منها فى المشروعات الصغيرة

جلول (v) النسب المئوية لآراء المتخصصين نحو إمكانية إقامة مشروع صغير قائم على القطعة المنفذة

\begin{tabular}{|c|c|c|c|}
\hline \multicolumn{3}{|c|}{ مستويات الأداء } & \multirow{2}{*}{ بنود التقويم } \\
\hline غيرمناسب & إلى حد ما & مناسب & \\
\hline - & - & $\%$ & ملدى ملائمة القطعـة المنفـــة مـــ ذوى الإمكانيـات \\
\hline$=$ & $\%$ & $\% .9$. & ملى ملائمة القطعة المنفذة لإقامة مشروع صفير \\
\hline- & $\%$ & $\%$ & ملى ملائمة سعر البيع للقطعة المنفذة \\
\hline
\end{tabular}

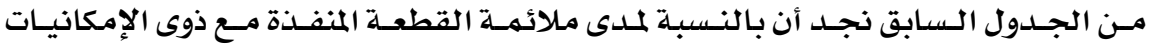

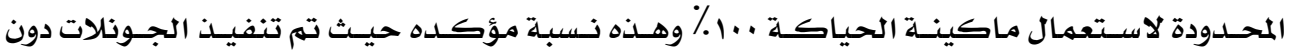
إستخدام ماكينـة الحياكة ، أما بـالنسبـة لكل من مدى مـلائمهة القطعة المنفـذة لإقامـة مسشروع صغير

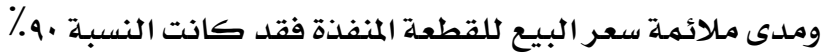

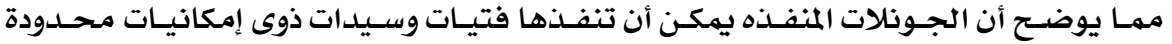

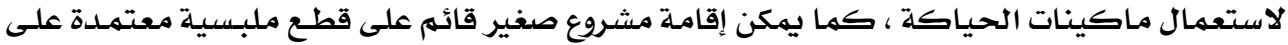
تجميـع أجزاءها بغرزة الفرع يسـاعد على حيـاة أفضل.

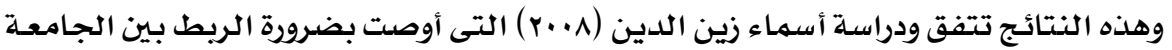
وسوق العهل مـن خلال إعداد كوادر فنيـة جامعيـة تتطلبها سوق العهل على مستوى عالى من الكفاءة. كهـا يتفـق مـع التوصـيـات التـى اقترحتهـا دراسـة كـل مـن عـلا عبـد الـلاه وسـالى الـوراقى

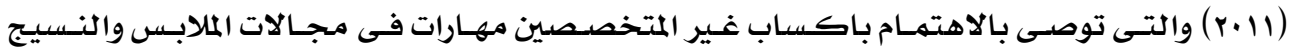
كالتطريز اليدوى ، وهذه الدراسلة بصدد إنتاج قطع ملبسيـة معتمدة على غـرزة الفـرع وعدم إستخدلام ماكينات الحياكة.

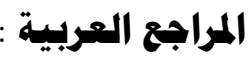

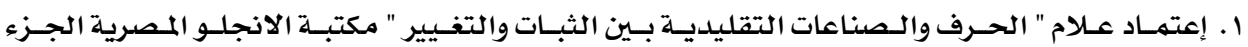

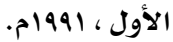

r. إيهـان رأفت سـعد السـيد : " دراسـة القـيم الوظيفيـة والجمـاليـة للجلـود وتطبيقاتها فى صسناعة الملابس" رسالة ماجستير ، قسه الملابس الجاهزة ، كلية الفنون التطبيقية ، جامعة حلوان ، ^• +. م. r. إيمان عطية الشوادفى : "الاستفادة من بعض تقنيات زخرفة الجلود فى إنتاج مكمـلات أزيـاء المرأة" رسـالة ماجستير ، قسهم التربية الفنية ، كلية التربية النوعية ، جامعة المنصورة ، ب. بrم. ع. إيمان محمد حسـين مصطفى : "القيم الجمالية لأسلوب تجاور الخامـات وتطبيقها على الملابس الجلدية" رسالة ماجستير ، قسى الملابس والنسيـج ، كلية الاقتصاد المنزلى ، جامعة حلوان ، 11 +rم. ه. إيهان محمدل عادل الدسـوقى "تأثير إستخدام بقايـا الجلـود الصناعية على القيمـة الجماليـة والوظيفيـة

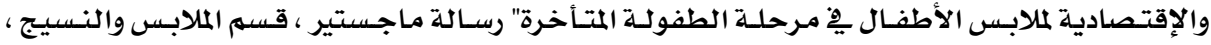
كلية الاقتصاد المنزلى ، جامعة المنوفية ، 11 إبم. 
T. أسماء سـامى عبد العاطى سـويلهم "تاثير اخـتلاف بعض الااسـاليب التطبيقيـة فى مـراحل تصنيع الجلـل الطبيعى والصناعى على الخواص الوظيفية للمنتج النهائى" رسـالة ماجستير ، قسم الملابس والنسيـج ،

$$
\text { كلية الاقتصاد المنزلى ، جامعة المنوفية ، ب...rم. }
$$

V. أسماء مححمود احمد محمد زين الدين : "أسس وتقنيـات زخرفة الملابس الجلديـة بـالتطريز الالى" رسـالة

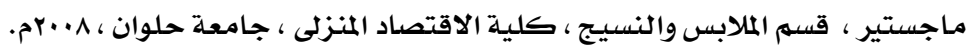

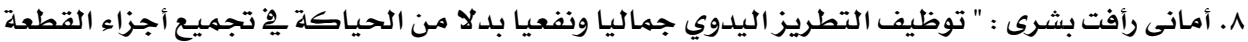

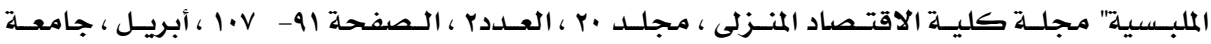

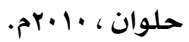

9. دعاء عبد المجيد ابراهيهم جعفـر :" إمكانيـة إثراء القـيم الجماليـة للمفروشـات المنزليـة بـاستخدام اسـلوب

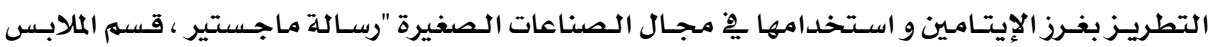

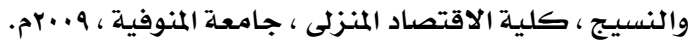

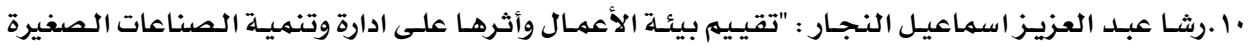

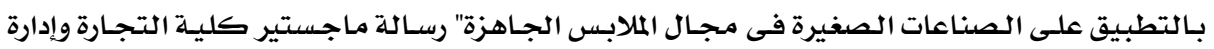

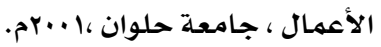

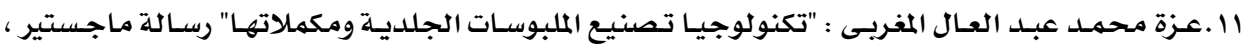

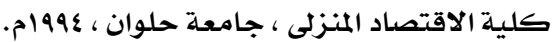

r ا .علا يوسف عبد الله و سـالى فوزى الكوراقى : "فاعليـة أسـلوب التعلهم الذاتى فى إكسـاب غير المتخصصـين

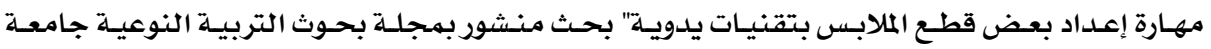

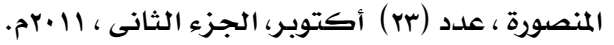

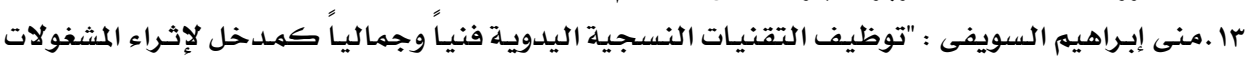
الجلدية وتطبيقاتها فى مـراكز الشباب" رسـالة مـاجستير غير منشورة ، كليـة التربيـة الفنيـة ، جامعسة

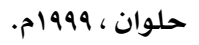

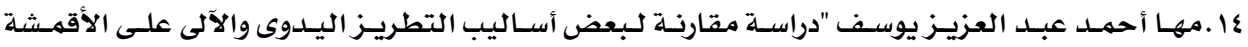

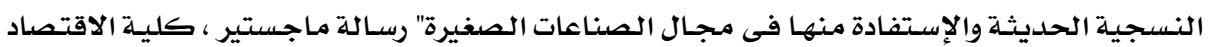

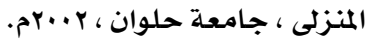

10 .نيفين عبــ الوكيـل إبراهيم إدريس : "الإسـتفادة مـن بقايـا الجلـود لإثراء القيمـة الوظيفيـة والجماليـة

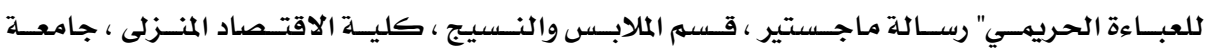

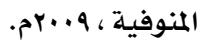

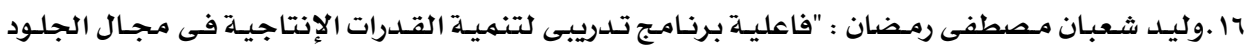

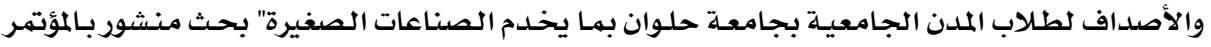

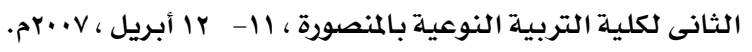

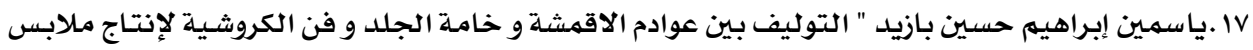

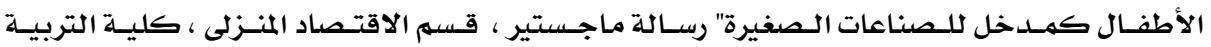




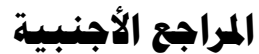

18. Gillow, John, and Bryan Sentance: "World Textiles" Bulfinch Press / Little, Brown. ISBN 0-8212 -2621, 1999.

19. Harris, Christine:"Wool Embroidery for Babies" Sally Milner Publishing" 1992.

20. Ollard, Caroline:"The Complete Book of Needle Crafts" Eagle moss publications Limited 1984. 
An experimental study for some hand embroidery stitches in implementing Leather Skirts For benefit in small projects

Preparation

Assist. Prof.Dr/ Amal Mohammed el-Fayoumi *

Dr/ Rabab Taher Abd el Latif

\section{Abstract:}

Some studies confirm that the production of leather clothes require an especial style in implementing and finishing as well as the used tools and machinery. This study aimed to simplify dealing with Leather in production pieces of clothes generally and skirt specially by assembling pieces with hand embroidery stitches ! to reduce the difficulty of dealing with Leather using a sewing machine as well as to give the aesthetic appearance for executing pieces with embroidery stitches and enriching the value of hand embroidery because of its high artistic value, also small projects can be done to help individuals for better life.

The present study used experimental method, the sample of the study was (6) graduates of Home Economics and Specific Education Faculties aged between 22 to 26 years old.

\section{The main results of the study:}

- Branch stitch is appropriate for assembling pieces of leather skirts implemented in terms of both functional and aesthetic performance.

- Produced skirts can be implemented by girls and women with limited ability of sewing machines use.

- A small project can be established based on pieces of clothes from synthetic leather assembled with branch stitch.

"Assistant professor of clothes and textile, Home Economics Department, Faculty of Specific Education, Damietta University.

"Teacher of clothes and textile, Home Economics Department, Faculty of Specific Education, Damietta University. 